\title{
$\mathrm{FCTC}$ 의 발전에 따른 정책전략의 개발
}

최은진

한국보건사회연구원
접수일 : 2012년 12월 11일 수정일 : 2012년 12월 27일 승인일 : 2012년 1월 7일

*교신저자 : 최은진 한국보건사회연구원 서울시 은평구 불광동 산 42-14 (우 122-705

Tel: 02-380-8249

Fax: 02-353-0344

E-mail: eunjin@kihasa.re.kr

\section{Policy Strategy for Tobacco Control in Korea; Lessons from the FCTC Development}

\author{
Eun Jin Choi* \\ Korea Institute for Health and Social Affairs, Seoul, Korea
}

The purpose of this manuscript was to review policy indicators of tobacco policy in the National Health Promotion Plan (Health Plan 2020) in Korea in the perspectives of the Framework Convention on Tobacco Control (FCTC). In November, 2012, at the 5th Conference of the Parties to the FCTC held in Seoul, the protocol to eliminate illicit trade in tobacco products has been adopted by the Parties. Eradication of smuggling and illegal manufacturing of tobacco products would prevent revenues losses in addition to reduced accessibility of tobacco among youth and vulnerable population. Both price and non-price measures for demand reduction would need adequate outcome indicators. The tobacco policy indicators in the Health Plan 2020 in Korea included 6 category of objectives. They included reduction of adolescent smoking rate, reduction of adult smoking rate, delay of smoking initiation age, increased smoking cessation intention and quit attempts, reduction of secondhand smoking rate, and increasing designation of non smoking area. These indicators were related to plans of tobacco policy and programs, which included smoking prevention program, smoking cessation support program, protection of non-smokers program, and non-smoking environment development program. The indicators need to be used in related future tobacco control policy and program development. Those outcome measure development has to be more compatible with policy recommendations of the FCTC.

Key Words: Tobacco; Policy; Smoking

Copyright (c) 2013 by Journal of the Korean Society for Research on Nicotine and Tobacco.
서

\section{론}

우리나라는 2000년대 초반부터 국민건강증진종합계획을 개발하여 왔고, 2010년에 제3차국민건강증진종합계획(Health Plan2020)을 수립한 바 있다. 건강수명연장과 형평성제고를 위한 금연정책의 목표지표는 청소년 흡연율감소, 성인흡연 율 감소, 흡연시작연령감소, 금연시도증대, 간접흡연경험율 감소, 금연구역확대 등이 포함되어 있다. 특히 흡연율감소지
표에는 하위 지표로 소득수준간의 흡연율격차감소지표가 포 함되어 있다. 청소년 흡연율의 형평성지표로는 일반고등학 교와 실업계고등학교간의 흡연율격차감소의 지표가 있다. 우리나라 성인흡연율은 지난 10년간 감소되었으나 OECD국 가의 다른 선진국가 비교할 때 남자흡연율은 최고수준을 유 지해 왔다. 2005년부터 OECD국가의 남자평균흡연율이 $30 \%$ 이내로 하락세를 보이게 된 것은 선진국들이 담배규제를 위하여 담뱃세 인상정책, 담배유통규제 등 금연정책을 강화 
했기 때문이다. 우리나라도 FCTC에 부합하는 실질적인 금 연정책이 도입되지 않는 한 국민건강증진종합계획의 금연목 표 20\%대 달성은 어려울 것으로 전망되고 있다. 가격정책과 비가격정책의 균형있는 발전이 필요하고, FCTC에 부합하는 정책개발이 필요하다. 본 종설에서는 협약의 이행성과를 극 대화 하기 위하여 정책적인 개선과제를 검토하는 데 목적이 있다.

\section{본 론}

\section{1. 담배규제기본협약의 발전과 시사점}

2012년 11월 서울에서 개최된 세계보건기구(WHO) 담배 규제기본협약(FCTC)의 제 5 차 당사국총회에서 보건분야의 역사적인 성과가 거둬졌다. 담배제품의 불법거래근절 의정 서가 만장일치로 채택된 것이다. 이로써 담뱃값 인상으로 우 려되는 밀수, 위조 등 담배제품의 불법거래를 방지하기 위한 국제적 공조체제 기반이 마련됐다. 의정서의 목표는 담배공 급의 연결망을 규제하는 국제적인 협력에 있으며, 담배제품 의 불법거래를 방지하기 위하여 추적시스템을 마련하는 데 있다. 현재 $\mathrm{FCTC}$ 협약에는 176 개 당사국이 참여하고 있다. 이 협약의 특징은 담배의 수요와 공급을 감소시키는 데 초점 을 두고 있다. 담배제품의 수요감소를 위해서 가격정책과 금 연구역확대 및 금연지원 등 비가격정책을 동시에 추진하는 것을 권고하고 있다. 협약 제6조의 담배가격 인상 및 면세담 배규제 등 가격정책은 담배접근성을 감소시켜 청소년들의 담배소비를 줄이고 재원확보를 통해 금연 및 건강증진사업 을 지원하는 데 목적이 있다. 담배가격정책은 담배유통규제 및 금연구역확대와 같은 비가격정책이 맞물려 돌아갈 경우 흡연율 및 담배소비를 감소시킬 수 있고, 국민보건 측면에서 사회경제적 부담 감소 효과를 얻을 수 있다. WHO의 Tobacco Free Initiative에서 권고한 바 있는 담배규제정책 의 핵심정책 MPOWER는 기술적인 정책평가기준(Technical Measures)이다. MPOWER는 수요감소정책에 해당하며, 담배사용 및 정책의 모니터링(Monitor tobacco use and prevention policies), 간접흡연으로부터의 보호(Protect people from tobacco smoke), 금연을 지원하는 서비스 (Offer help to quit tobacco use), 담배의 위험성에 대한 경 고(Warn about the dangers of tobacco), 담배광고판촉후 원의 금지강화(Enforce bans on tobacco advertising, pro- motion and sponsorship), 담뱃세인상(Raise taxes on tobacco) 등을 포함한다.

MPOWER 외에 수요감소를 위하여 권고되는 정책은 담 배의 성분규제 및 성분공개에 관한 정책이다(협약 제9조 및 10조). 담배연기에는 4,000여종의 화학물질이 있고, 43가지 의 발암물질이 있다.(1) 담배제품에는 1,400 여종의 첨가물 질이 있어 30 에서 150 가지의 다른 향(flavor)을 내게 할 수 있는데, 1990년대에 이미 European Union에서는 600여종 의 첨가물만을 허용한 바 있다. 식품으로 사용할 때 안전한 물질이라고 해도, 담배에 첨가되어 사용될 때의 위해성에 대 해서 알려지지 않은 부분이 많기 때문에 더 강한 규제가 필 요하다.(2) 미국의 식품의약품안전청(FDA)에서는 담배제 품의 원료와 첨가물, 방출물질에 대한 규제를 하고, 담배회 사로 하여금 93 가지 물질에 대한 측정과 보고를 하도록 하고 있다.

흡연문제를 해결하기 위하여 전 지구적 협력이 필요하다 는 데에 세계보건기구가 공식적으로 나선 이유는 담배생산 국의 대부분이 선진국인 반면 담배소비국은 대부분 저소득 국가 또는 개발도상국가이기 때문이다. 개발도상국가의 인 구는 계속 증가하는데, 아동 및 청소년을 담배로부터 보호할 수 있는 정책적 기반이 거의 없었기 때문이다.

2000년 세계보건기구 사무총장이었던 Gro Harlem Brundtland박사가 담배로 인한 건강폐해감소를 위해 제시 한 금연정책방향은 다음의 네가지로 요약되며, 협약의 근간 이 되는 정책방향이다. 첫째, 청소년과 비흡연자들이 흡연 을 시작하지 않도록 예방하는 것, 둘째, 흡연자들이 금연할 수 있도록 지원하는 것, 셋째, 비흡연자(태아포함)들이 담배 연기에 노출되지 않도록 하는 것, 넷째, 담배제품에 있는 위 해물질의 수준을 낮추는 것 등이다.(3)

담배규제기본협약은 2차례의 실무회의와 6차례의 협상 회의를 거쳐 2003년 5월 21일 제53차 보건총회(World Health Assembly)에서 192개 WHO 회원국의 만장일치로 채택되었다. 2004년 11월 30일 협약 발효의 필요조건인 40 개국이 비준함으로써 2005년 2월 27일부터 발효되었다. 2006년 제1차 당사국총회를 시작으로 협약8조의 이행을 위 한 가이드라인 개발이 시작되었고, 2007년 2차총회에서 첫 번째 가이드라인이 탄생했다. 2008년 2월부터는 담배제품 의 불법거래근절에 관한 의정서개발을 위하여 당사국간의 협상이 진행되었다. 지금까지 7개의 가이드라인이 승인되 
었고, 1 개의 의정서가 승인되었다. 승인된 가이드라인은 제 5조 3항(담배회사의 활동으로부터 공중보건정책의 보호), 제8조(담배연기노출로부터의 보호), 9 조 및 10 조(담배제품 성분규제 및 담배제품의 공개제도; 부분적 가이드라인을 승 인한 상태임), 11 조(담배제품의 라벨규제 및 건강경고제도), 12 조(금연교육홍보훈련 등), 13 조(담배광고판촉후원), 14 조(담배의존 및 금연에 대한 수요감소정책) 등이다. 현재 운 영중인 가이드라인 작업반은 9조 및 10 조의 작업반과 17 조 및 18 조(담배농가의 전환), 6조(담배가격정책) 등이다.(4)

\section{2. 흡연관련 지표의 동향}

\section{1) 흡연으로 인한 사망}

우리나라 국민의 흡연기인 사망률은 2001 년 기준 인구 10 만명(당) 단 86.3명으로 분석된 바 있다.(5) 1998년 및 2001 년 국민건강영양조사를 기조로 한 분석에서 흡연자는 비흡 연자에 비하여 사망확률이 2 배이상 높은 것으로 나타난바 있다.(6) 2007년 흡연현황을 기준으로 사회경제적 비용손실 은 약 5조4천억원인 것으로 분석되었다. 여기에는 직접적인 의료비와 간접적인 비용(조기사망으로 인한 소득 및 생산성 손실 등)이 주요 변수로 포함되었다. 한편 흡연관련 기대여 명에 대한 분석결과 2010년 기준 30세 남자흡연자의 기대여 명은 47.61년으로 나타나 비흡연자의 기대여명 54.04년과 많은 차이를 보인 것으로 나타났다.(7)

세계보건기구의 2004년 기준 흡연기인 사망률 보고서에 서 세계적으로는 전체사망의 약 $12 \%$ 의 기여율을 보였고(남 자 $16 \%$, 여자 $7 \%)$, 우리나라 국민의 사망 기여율은 남자 $21 \%$, 여자 $15 \%$ 등으로 다른 선진국에 비하여 높은 수준이었
다.(8) 우리나라 통계청의 보고에 의하면, 2011년 생명표에 의거하여 암으로 사망할 확률은 21.6이고 남자가 암으로 사 망할 확률은 $27.7 \%$ 로 나타난바 있다. 우리나라 국민이 자살 로 사망할 확률은 $3.1 \%$ 로 나타난 것에 비하여 매우 높은 수 치였고, 그만큼 만성질환으로 인한 사망률 감소를 위한 노력 이 더 필요함을 알 수 있었다.(9)

\section{2) 흡연율 지표}

우리나라 성인남자흡연율은 $\mathrm{OECD}$ 국가중 최고 수준이 다.(10) 질병관리본부의 국민건강영양조사에 의하면 우리 나라 성인의 흡연율은 지난 10 여년간 감소해 왔으나, 최근 에는 답보상태에 있다. 청소년의 흡연율은 남자흡연율은 다 소 증가추세이고, 여자흡연율은 다소 감소추세에 있다(그림 1). $(11,12)$

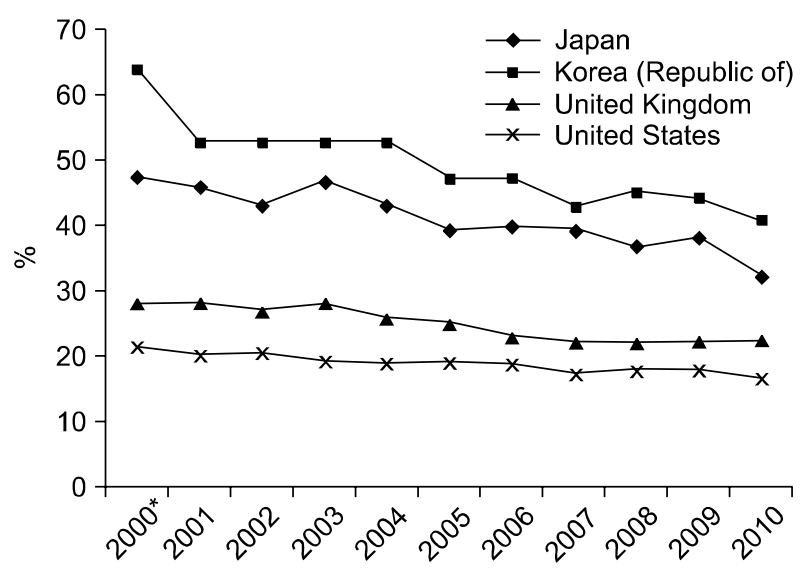

Figure 1. Male smoking rate among selected OECD countries. * The Korean data in 2000 is from the 1998 National Health and Nutrition Survey, Daily smokers only. Source: OECD Healthdata, 2012.

Table 1. Experience of getting smoking prevention education during the past year.

(Unit: \%)

\begin{tabular}{lrrrrr}
\hline \multirow{2}{*}{ Age } & \multicolumn{5}{c}{ Year } \\
\cline { 2 - 6 } & 2007 & 2008 & 2009 & 2010 & 2011 \\
\hline $19-29$ & 12.6 & 12.8 & 11.9 & 13.4 & 16.5 \\
$30-39$ & 7.4 & 7.2 & 7.9 & 9.6 & 7.2 \\
$40-49$ & 6.2 & 6.2 & 5.9 & 4.5 & 7.4 \\
$50-59$ & 4.3 & 3.4 & 2.5 & 1.9 & 1.9 \\
$60-69$ & 1.8 & 1.6 & 2.8 & 7.5 & 3.6 \\
$70+$ & 1.8 & 7.0 & 7.3 & 7.5 & 7.1 \\
Total $^{*}$ & 6.9 & & & 7.5 \\
\hline
\end{tabular}

*Age Standardised rate based on 2005 population estimation, except for the data in 2011. Source: Korea Centers for Disease Control, 2010 National Health Statistics; Korea Centers for Disease Control, 2011 National Health Statistics. 
Table 2. Adults' exposure to tobacco smoke in workplace.

\begin{tabular}{lcccccc}
\hline & 2005 & 2007 & 2008 & 2009 & 2010 & 2011 \\
\hline Total $^{\dagger}$ & 36.8 & 45.9 & 45.4 & 45.7 & 49.2 & 44.3 \\
Male & 44.5 & 55.1 & 53.4 & 53.2 & 58.6 & 53.9 \\
Female & 31.8 & 36.4 & 38.2 & 39.4 & 41.8 & 36.6 \\
\hline
\end{tabular}

* Age Standardised rate based on 2005 population estimation, except for the data in 2011. ${ }^{\dagger}$ Definition of the exposure: Current nonsmokers lincluding past smokers)'s experience of exposure to tobacco smoke in the indoor workplace, aged 19 and over. Source: Korea Centers for Disease Control, 2010 National Health Statistics; Korea Centers for Disease Control, 2011 National Health Statistics.

Table 3. Youth' exposure* to tobacco smoke at home.

(Unit: \%)

\begin{tabular}{llllllll}
\hline & 2006 & 2007 & 2008 & 2009 & 2010 & 2011 & 2012 \\
\hline Total & 40.3 & 46.9 & 46.8 & 41.2 & 40.8 & 39.6 & 32.9 \\
Male & 38.2 & 46.2 & 46.0 & 40.1 & 40.3 & 38.5 & 31.1 \\
Female & 42.6 & 47.7 & 47.6 & 42.4 & 41.5 & 40.8 & 34.8 \\
\hline
\end{tabular}

*Experience of exposure to tobacco smoke at home more than one week among middle and high school students. Source: Korea Centers for Disease Control, Youth Health Behavior Online Survey, 2012.

Table 4. Tobacco policy development in the National Health Promotion act.

\begin{tabular}{|c|c|c|}
\hline Year & Contents & Relevant FCTC article \\
\hline \multirow[t]{2}{*}{2005} & Rectify Framework Conventionon on Tobacco Control (2005.5.16) & \\
\hline & Provision of free smoking cessation clinic through 250 local public health centers & $\begin{array}{l}\text { Demand reduction measures concerning tobacco dependence } \\
\text { and cessation (14) }\end{array}$ \\
\hline \multirow[t]{4}{*}{2006} & Expanding non smoking area in small workplaces and factories & Protection from exposure to tobacco smoke (8) \\
\hline & $\begin{array}{l}\text { Increase proportion of health warning label to } 30 \% \text { of front and back of a cigarette } \\
\text { package }\end{array}$ & Packaging and labelling of tobacco products (11) \\
\hline & Telephone based quit-line & $\begin{array}{l}\text { Demand reduction measures concerning tobacco dependence } \\
\text { and cessation (14) }\end{array}$ \\
\hline & $\begin{array}{l}\text { Discontinue of exemption of health promotion tax on low price tobacco products/ } \\
\text { collection of health promotion tax from cigarette manufacturers }\end{array}$ & Price and tax measures to reduce the demand for tobacco $(6)$ \\
\hline \multirow[t]{2}{*}{2007} & Adding 6 cancer causing chemicals on health warning labels & Packaging and labelling of tobacco products (11) \\
\hline & Reduction of military duty free tobacco products & Price and tax measures to reduce the demand for tobacco (6) \\
\hline 2008 & Expanding non smoking areas to elevators, hallways and toilets & Protection from exposure to tobacco smoke (8) \\
\hline 2009 & Discontinue tax free tobacco products provided in military & Price and tax measures to reduce the demand for tobacco (6) \\
\hline \multirow[t]{2}{*}{2010} & Local governments have the authority to designate non smoking area and levy fine & Protection from exposure to tobacco smoke (8) \\
\hline & Earmark health promotion tax on electronic cigarettes (221 KRW per 1 ml) & Price and tax measures to reduce the demand for tobacco (6) \\
\hline \multirow[t]{4}{*}{2011} & Expanding designation of non smoking area in restaurants & Protection from exposure to tobacco smoke (8) \\
\hline & $\begin{array}{l}\text { Amending health warning on tobacco packages and included telephone number of } \\
\text { the helpline }\end{array}$ & Packaging and labelling of tobacco products (11) \\
\hline & Banning information of additives on tobacco packages & Packaging and labelling of tobacco products (11) \\
\hline & Reducing tobacco advertisement on printed periodicals to 10 from 60 times a year & Tobacco advertising, promotion and sponsorship (13) \\
\hline
\end{tabular}

Source: Choi, EJ, Suh MK, Park EJ, Lee CH, Evaluation of the National Anti-smoking campaign program from 2005 to 2011, Korea Health Promotion Foundation, Korea Institute for Health and Social Affairs, 2011. 
Table 5. Tobacco control related policy indicators in the National Health Plan 2020.

\begin{tabular}{|c|c|c|c|c|}
\hline Objectives and indicators $^{\dagger}$ & 2005 & 2008 & 2020 & Related program* \\
\hline 1-1. Reduce adolescent smoking rate & & & & $A, B, D$ \\
\hline Middle and high school male students & $14.3 \%$ & $16.8 \%$ & $12.0 \%$ & \\
\hline Middle and high school female students & $8.9 \%$ & $8.2 \%$ & $6.0 \%$ & \\
\hline $\begin{array}{l}\text { 1-1-1. Narrow the smoking rate gap between general and technical } \\
\text { high school students }\end{array}$ & & & & $A, B, D$ \\
\hline General high school male students & $16.4 \%$ & $19.2 \%$ & - & \\
\hline Technical high school male students & $37.9 \%$ & $36.8 \%$ & - & \\
\hline Gap & $21.5 \%$ & $17.6 \%$ & $9.0 \%$ & \\
\hline General high school female students & $7.5 \%$ & $6.4 \%$ & - & \\
\hline Technical high school female students & $29.6 \%$ & $25.4 \%$ & - & \\
\hline Gap & $22.1 \%$ & $19.0 \%$ & $9.0 \%$ & \\
\hline 1-2. Reduce adult smoking rate & & & & $A, B, D$ \\
\hline Male adult smoking rate & $51.6 \%$ & $47.7 \%$ & $29.0 \%$ & \\
\hline Female adult smoking rate & $5.7 \%$ & $7.4 \%$ & $6.0 \%$ & \\
\hline 1-2-1. Reduce smoking rates' gap among regions and income levels & & & & $A, B, D$ \\
\hline Male smoking rate in cities & $51.36 \%$ & $47.4 \%$ & - & \\
\hline Male smoking rate in rural & $56.43 \%$ & $49.1 \%$ & - & \\
\hline Gap & $5.07 \%$ & $1.7 \%$ & $1.0 \%$ & \\
\hline Female smoking rate in cities & $5.93 \%$ & $7.8 \%$ & - & \\
\hline Female smoking rate in rural & $5.02 \%$ & $4.0 \%$ & - & \\
\hline Gap & $0.91 \%$ & $3.8 \%$ & $2.0 \%$ & \\
\hline Male smoking rate in the lowest income quartile & - & $55.3 \%$ & - & \\
\hline Male smoking rate in the highest income quartile & - & $39.9 \%$ & - & \\
\hline Gap & - & $15.4 \%$ & $8.0 \%$ & \\
\hline Female smoking rate in the lowest income quartile & - & $8.9 \%$ & - & \\
\hline Female smoking rate in the highest income quartile & - & $6.3 \%$ & - & \\
\hline Gap & - & $2.6 \%$ & $1.5 \%$ & \\
\hline 1-3. Delay smoking initiation age & & & & A \\
\hline Smoking initiation age & 12.1 & 13 & 15 & \\
\hline Daily smoking initiation age & 14.1 & 14.3 & 15 & \\
\hline Male smoking initiation rate before middle school & $14.9 \%$ & $10.3 \%$ & $5.0 \%$ & \\
\hline Female smoking initiation rate before middle school & $9.4 \%$ & $6.5 \%$ & $3.0 \%$ & \\
\hline Male smoking rate aged $19-29$ & $55.5 \%$ & $53.6 \%$ & $35.0 \%$ & \\
\hline Female smoking rate aged 19-29 & $6.0 \%$ & $12.7 \%$ & $10.0 \%$ & \\
\hline 1-4. Increase smoking cessation intention and quit attempts & & & & $B, D$ \\
\hline Youth current smokers' intention of quitting smoking & - & $43.4 \%$ & $80.0 \%$ & \\
\hline Adult current smokers' quit attempts & $60.86 \%$ & $57.3 \%$ & $80.0 \%$ & \\
\hline Adult current smokers' intention of quitting smoking & $10.96 \%$ & $18.1 \%$ & $40.0 \%$ & \\
\hline Registration rate in smoking cessation program & - & & $10.0 \%$ & \\
\hline Utilization of telephone helpline of smoking cessation counselling & - & & $5.0 \%$ & \\
\hline 1-5. Reduce secondhand smoking rate & & & & $C, D$ \\
\hline Male secondhand smoking rate in workplace & $53.7 \%$ & $46.7 \%$ & $5.0 \%$ & \\
\hline Female secondhand smoking rate in workplace & $39.8 \%$ & $25.7 \%$ & $2.0 \%$ & \\
\hline Male secondhand smoking rate at home & $7.1 \%$ & $5.9 \%$ & $1.0 \%$ & \\
\hline Female secondhand smoking rate at home & $23.9 \%$ & $20.4 \%$ & $5.0 \%$ & \\
\hline Youth secondhand smoking rate at home & - & $46.8 \%$ & $5.0 \%$ & \\
\hline 1-6. Increasing designation of non-smoking area & & & & D \\
\hline Designation of non smoking facilities & $\begin{array}{l}\text { Schools, medical } \\
\text { facilities, nurseries }\end{array}$ & - & $\begin{array}{l}\text { Schools, medical facilities, nurseries, } \\
\text { workplaces of } 50 \text { or more employees }\end{array}$ & \\
\hline Designation of non-smoking areas & Large buildings & - & Small work places & \\
\hline
\end{tabular}

*Names of Policy and Programs: A. Smoking prevention program; B. Cessation support program. C. Protection of Non-smokers program; D. Non-smoking environment development program. Source : Ministry of Health and Welfare, Korea Institute for Health and Social Affairs, The National Health Plan 2020 (The Third National Health Promotion Plan), 2010. 
2005년 국민건강영양조사의 보건의식행태조사결과에 의하면 약 $95 \%$ 의 성인이 지난 1 년간 금연캠페인을 경험한 것으로 나타난 바 있다. 흡연예방 및 금연교육경험률은 2007년 6.9\%에서 2011년 7.5\%로 증가한 것으로 나타난 바 있다. 연령별로 살펴보면, 20 대의 경험률이 가장 높고, 30 대 부터는 급감하는 것을 볼 수 있다(표 1).

우리나라 국민건강영양조사결과에 의하면 지난 5년간 성 인의 직장 실내간접흡연노출율은 개선되지 않고 있는 것으 로 나타나고 있다. 청소년의 가정내 간접흡연노출율은 2008 년 이후 $46.8 \%$ 에서 $32.9 \%$ 로 감소하였으나 남자보다는 여자 의 간접흡연경험율이 높게 나타나고 있다(표 2,3).(13) 세계 보건기구(WHO)는 전 세계적으로 어린이 인구의 절반에 해 당하는 약 7억명의 어린이가 간접흡연에 노출되어 있다고 추정하며, 캐나다는 약 $47 \%$ 의 어린이가 가정에서 간접흡연 에 노출되어 있는 것으로 추정하고 있다. 2004년 미국 전체 에서 간접흡연에 따른 폐암 또는 심장질환으로 손실된 경제 비용은 의료비를 제외하고 약 3 조 8 천억원에 달하는 것으로 추산된 바 있다.(14)

\section{3. 금연관련 법제도의 개발 동향}

우리나라에서 보건정책으로서 본격적인 금연정책을 추 진한 것은 1995년 국민건강증진법의 제정에서 부터이다. 담 배세인상 및 금연홍보 등의 사업으로 흡연율감소에 기여한 것으로 평가되고 있다. 지난 10년 동안 국민건강증진기금에 의한 금연사업(금연홍보, 금연클리닉 사업 등)이 강력하게 추진된 것은 금연사업예산확보가 많은 영향을 준 것으로 분 석된 바 있다(표 4).(15,16)

\section{4. 국민건강증진종합계획 목표달성을 위한 과제}

우리나라는 2000년대 초반부터 국민건강증진종합계획 을 개발하여 왔고, 2010년에 제3차국민건강증진종합계획 (Health Plan2020)을 수립한 바 있다. 건강수명연장과 형평 성제고를 총괄목표로 수립한 바 있다. 건강생활실천확산, 만성질환발병위험요인관리, 감염질환관리, 안전환경보건, 인구집단 건강관리, 사업체계 관리 등의 분야에서 32 개의 중점과제가 있다. 건강생활실천분야의 첫 번째 중점과제인 금연정책과제에서는 흡연예방과 흡연자의 금연, 금연을 지 지하는 환경조성, 비흡연자보호 등을 목표로 하고 형평성 감 소를 목표로 한다. 금연정책목표달성을 위한 지표는 성인 및
청소년의 흡연율 감소, 흡연율 관련 건강형평성 제고, 흡연 시작연령의 지연, 금연시도율 및 금연의지 증가, 간접흡연 감소 및 금연구역확대 정책 등으로 요약할 수 있다.(17) FCTC협약을 반영하고 이행의 성과를 높이기 위해서는 추 가적인 지표의 개발이 필요하다. FCTC이행보고서의 조사 항목들은 협약의 각 조항의 다양한 지표를 담고 있기 때문이 다. 담뱃갑 인상정책, 담배제품의 규제정책(제조성분공개, 라벨규제, 광고판촉후원금지 등), 다양한 계층을 위한 금연 교육홍보프로그램의 개발 등에 대한 전략과 지표가 확대개 발되어야 한다(표 5).

\section{결 론}

$\mathrm{FCTC}$ 협약이 발효된 이후 7 개 가이드라인과 1 개의 의정 서가 승인되었고, 앞으로도 추가적인 가이드라인개발을 위 한 작업반(Working group)을 가동하면서 발전될 것으로 전 망된다. 특히 주목할 부분은 그동안 176 개국이 비준하면서 협약의 이행과 더불어 흡연율 감소 등의 경향이 $\mathrm{OECD}$ 선진 국에서 두드러지게 나타나고 있다는 점이다. 이러한 사실은 협약이 근거중심의 협약이라는 것을 보여준다.

우리나라의 국민건강증진종합계획2020 상의 금연정책 목표인 흡연율 20\%대를 달성하기 위해서 FCTC에서 권고 하는 정책들을 균형있게 발전시킬 필요가 있다. 가격정책의 핵심은 담뱃세인상을 통하여 청소년의 흡연을 예방하고 담 배에 대한 접근성을 감소시키는 것과 확보된 세수를 건강증 진 및 금연지원에 사용하는 데 있다. 2004년말 담뱃세인상 이후 전혀 인상이 없는 담배가격은 흡연율을 답보상태로 가 게 하는데 기여하고 있다. 가격정책뿐만 아니라 보다 체계적 이고 강화된 비가격정책이 마련되어야 본격적인 흡연율감 소를 기대할 수 있을 것이다. 청소년의 흡연예방을 위한 담 배제품 규제 및 교육홍보사업, 흡연자의 금연을 지원하기 위 한 각종 금연사업, 금연구역 확대사업 등은 비가격정책의 핵 심사업이며 체계적이고 지속가능한 예산지원이 필요한 사 업들이다. 담뱃세 정책, 흡연예방 및 금연지원정책이 선순 환할 수 있도록 하기 위해 이해관계자, 보건의료인과 일반국 민을 설득해야 한다. 공공 및 민간부문에서 지속적인 논의의 장이 마련될 수 있도록 지원해야 하고, 흡연율 감소와 흡연 기인 사망률 감소를 위해 지속적인 연구지원도 확대되어야 한다. 


\section{참 고 문 헌}

1. MPOWER. Available from: http://www.who.int/tobacco/mpower/en/ index.html.

2. World Health Organization. Advancing Knowledge on Regulating Tobacco Products, Oslo Monograph, 2003. Available from: http:// www.who.int/tobacco/media/OsloMonograph.pdf.

3. Choi EJ, Suh MK, Lee YM, Roh JM, Park HJ, Hwang SK et al. The Results and Implications from the Third Conference of the Parties to the WHO FCTC and System Improvement of Tobacco Related Regulation (Law) in South Korea, Ministry for Health, Welfare and Family Affairs, Korea Institute for Health and Social Affairs, 2008.

4. Adopted guidelines [cited 2013 Jan 28]. Available from: http://www. who.int/fctc/protocol/guidelines/adopted/en/.

5. Yoo SL, Kim KH, Kim KK, Kim JH. Trends of smoking attributable mortality in Korea. Bogungwa Sahoegwahak 2005; 17: 133-48.

6. Kim HR, Kang YH, Yoon KJ, Kim CS. Socioeconomic Health Inequalities and Counter Policies in Korea (2004-03). Korea Institute for Health and Social Affairs 2004.

7. Jung YH, Ko SJ, Lee YG, Park SB, Lee JH. Lifetime cost of obesity and smoking and long-term effectiveness of health promotion, 2010, Korea Institute for Health and Social Affairs, Korea Health Promotion Foundation. 2010.
8. World Health Organization. WHO Global Report: mortality attibutable to tobacco. 2012.

9. National Statistical Officce. 2011 Life Table, Press Release. 2012.

10. OECD Healthdata 2012.

11. Korea Centers for Disease Control. 2010 National Health Statistics. 2011.

12. Korea Centers for Disease Control. 2011 National Health Statistics. 2012.

13. Korea Centers for Disease Control. Youth Health Behavior Online Survey. 2012.

14. Choi EJ, Suh MK, Meng KH, Lee JH, Cho HO, Park SP. Reasonable Tobacco Control Policy to Prevent Smoking, Korea Institute for Health and Social Affairs, Korea Health Promotion Foundation. 2009.

15. Choi, EJ, Meng KH, Kim WN, Seo HG, Kim CH, Cho SI et al. Policy measures for Safe Management of Tobacco Products and Smoking Prevention, Korea Institute for Health and Social Affairs, Korea Health Promotion Foundation. 2011.

16. Choi, EJ, Suh MK, Park EJ, Lee CH. Evaluation of the National Anti-smoking campaign program from 2005 to 2011, Korea Institute for Health and Social Affairs, Korea Health Promotion Foundation. 2011.

17. Ministry of Health and Welfare. Korea Institute for Health and Social Affairs, The National Health Plan 2020 (The Third National Health Promotion Plan). 2010. 